\title{
The Practice of Seismic Management in Mines- How to Love your Seismic Monitoring System
}

\author{
P.A. Mikula Kalgoorlie Consolidated Gold Mines, Australia
}

Eleven years of seismic monitoring has been the foundation for the current understanding and management of seismicity at Mt Charlotte mine. Knowledge gained by linking seismic monitoring to seismic management has allowed the mine to survive.

Seismic events possess elements of both fractal and chaotic behaviour. This gives valid basis firstly to collect seismic data, and secondly to expect that seismicity can be managed by tweaking mine designs. Engineers must collect and analyse both seismic event data and the detailed history of stope performance. This is a joint effort between computers doing the black box work, and engineers doing the value-adding. Suitable computer software and work schedules are vital in the busy mine office scenario. Examples of turning data into expertise are described, via studies of the validity of the links between seismicity and Mt Charlotte's expanded 21 empirical seismic design rules. A Self Organising Map study of the 21-Rules is in progress.

Some unusual yet important parallels between mine seismicity and Gothic Cathedral constructions of the 13th and 14th centuries, weather forecasting, hurricanes, and AFL football, are explored. The benefits reaped from the mine seismic monitoring system, and items that could have been done better, are described. Since none of this progress would be possible without seismic monitoring, the author can conclude "I love my Seismic Monitoring System."

\section{INTRODUCTION}

The author's experience at Mt Charlotte may be aptly summarised thus: "When I joined the mine in 1993 I was learning about seismicity. After 3 years I thought I knew everything. After 5 years I realised I knew nothing. Now I think I know something."

Yet by contrast, the general attitude of Mt Charlotte management and operators to seismicity is: "If Pete says it's OK, then it is." This attitude is particularly evident in the minutes prior to firing a major blast.

This paper is an exploration around those statements, of what substance has gone into the understanding and management of Mt Charlotte seismicity over the years. The mine seismic monitoring system is seen to be the essential foundation supporting the development of seismic management expertise at the mine.

Mining induced seismicity and associated ground control problems have a long history in Kalgoorlie's Golden Mile. Documented seismicity at Mt Charlotte mine goes back to March 1965, only three years after bulk mining methods were introduced to the mine. About 80 events of Richter magnitude 2 or greater have been recorded at Mt Charlotte since bulk mining started. Australia's first mine seismic monitoring system was commissioned in May 1994 (this was a PSS model supplied by the CSIR, South Africa, described by Mikula and Poplawski,1995), and had the dubious honour of recording the largest known Mt Charlotte event, Richter magnitude 3.5, in June 1998. Understandably, large events make managers, planners and engineers nervous, sometimes to the point of closing mines down. They rightly ask "why, and if so how, could mining still be done safely and profitably at Mt Charlotte?" But knowledge gained by linking seismic monitoring to seismic management has allowed the mine to survive. Mikula and Lee (2000) present the historical and geotechnical background of the mine in more detail.
Underground mining solutions to problems such as heat, communications and remote mining are available. While progress in seismicity is being made across the world by many dedicated workers, definitive solutions for seismic control are still distant. Figure 1 presents Mt Charlotte's seismic history since 1994, showing that good progress in seismic management has been achieved. The author hopes that documenting current Mt Charlotte understanding will add to the big picture and help provide another rung to the ladder.

In this paper all seismic event magnitudes are expressed as Richter or estimated Richter magnitudes unless otherwise noted.

\section{GOTHIC CATHEDRALS AND GOLD MINES}

Time spent learning from history is never wasted. The author is indebted in this section to an inspiring essay by Vaudeville (1999) discussing behaviour of structures, with particular reference to the Gothic Cathedral constructions of the $13^{\text {th }}$ and $14^{\text {th }}$ centuries. Stability of those edifices depends on the constituent parts forming a system, all parts being necessary, and some being proactive (flying buttresses and arches), and all obeying the laws of mechanics. Yet some constructions have collapsed, while others still stand, showing that unexpected catastrophic instability was a real issue.

Parts of Mt Charlotte have been mined little by little over many years until they resemble Swiss cheese. Likewise with the Gothic Cathedrals, over the years windows became larger, reducing massive stone walls to fragile interstitial pillars. While attractive for different reasons, larger stopes and larger windows both generate a concentration of energy and may suffer catastrophically in case of unanticipated circumstances. Documenting the instabilities is the first remedial step in both cases. 


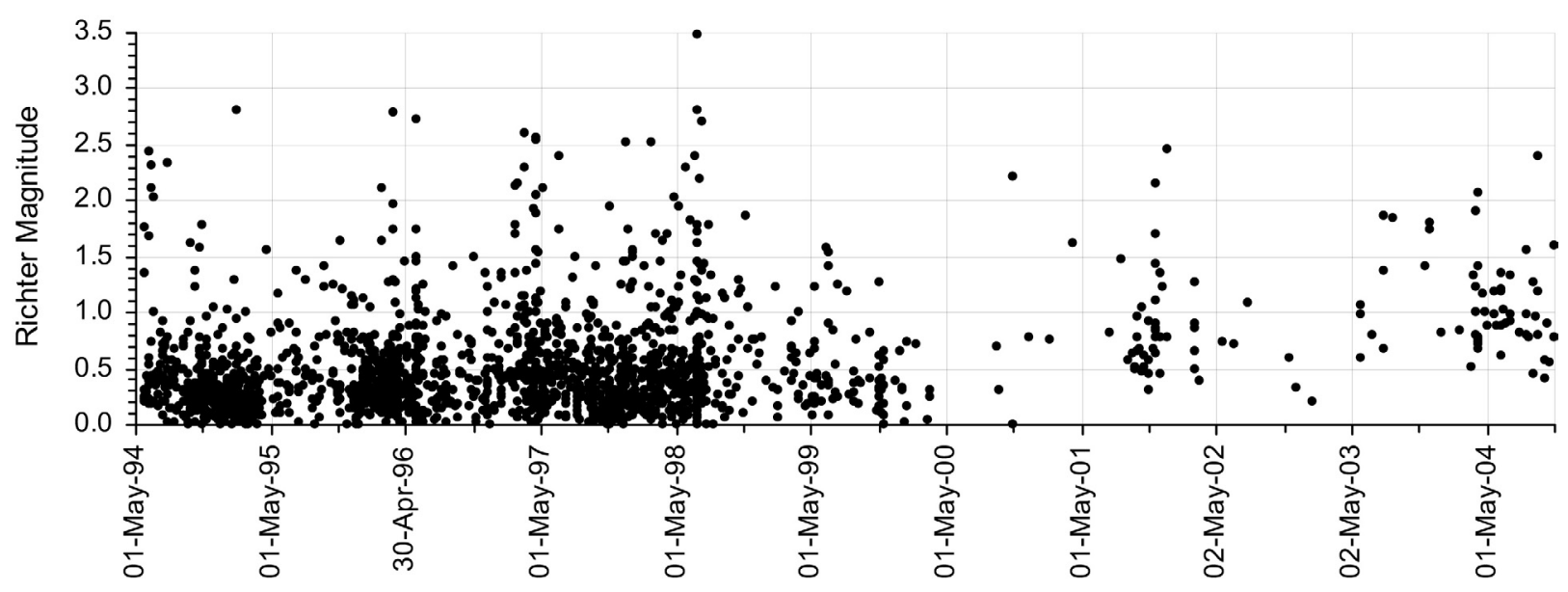

FIG. 1 Mt Charlotte mine seismic history since 1994. After June 1998 the number and magnitude of events decreased in line with mining method changes and generally reduced depth of production stopes

Stability depends on a partly planned and partly fortuitous arrangement of circumstances. How is stability anticipated? Vaudeville notes three ways:

1. Physical model - while precise, and demonstrating concepts, these models are always imperfect.

2. Calculation - essentially an intangible abstract thought process, a model on paper, weakened by the omission of external circumstances.

3. Computer simulation - systematically handle the complexities and present the correct result - reducing the computational risk, but at the cost of increasing the perception risks. For without thinking and reflecting on the task, the critical circumstance can go unseen.

Vaudeville observed the paradox that the better the calculations or computer simulations, and therefore the more trim and perfect the constructions, the less they can survive the unpredictable. The mining parallel, then, suggests it is prudent to force adequate thinking, by study and assessment on paper of every stope design, every large seismic event, every event cluster. A computer simulation is necessary to support thinking, not to substitute for it.

Fortunately for miners, rock surrounding the excavations has bulk, which by design or accident can permit stable equilibrium. The ancient stonemasons also tried to avoid instability by adding bulk to their designs. Each arch or column was figured with ten times the calculated minimum necessary cross-sectional area, so that a ten times stress concentration due to design or construction irregularities or other circumstances could be met without exceeding the perceived strength of the stone.

Elements of this historical illustration appear in surprisingly similar form in Mt Charlotte seismic experience. It is clear that catastrophic instabilities (large events) occur, as amply demonstrated in Figure 1 for Mt Charlotte. The remainder of this paper considers the remedy via the following three elements:

1. Documenting the nature of instabilities

2. Formulating design principles

3. Practical seismic management (allowing for variations, errors and unknowns)

\section{DOCUMENTING THE NATURE OF SEISMIC INSTABILITIES}

\subsection{The Basis for Collecting and Studying the Data}

Where there is a hazard, but the cause is not understood, the first step is to collect and analyse data. How is this applied to seismicity which appears random at first glance? What is the analysis method for something that appears so fuzzy and fussy? The answer lies in the mathematics:

Fractal behaviour. Seismic events may appear random, but occur in clusters (Hudyma et al., 2003). Seismic event clusters show fractal characteristics, i.e. clusters are selfsimilar (subsets in time or space look like the whole) and are independent of scale (they look similar when zoomed in).

This is important and extremely useful. Fractal character over time means that analysis of cluster subsets gives valuable insight into future events in that cluster. Seismicity reveals its character early, in smaller events and lesser damage, giving time to study why it is happening, and how to respond. An example is shown in Figure 2 for the MOB4 stope.

This quite simply means that if seismicity is monitored and analysed, seismic hazard can begin to be understood. By contrast, no monitoring system means no history and no learning.

Chaotic behaviour. Seismicity also shows elements of chaotic behaviour. Chaos theory deals with the behaviour of certain nonlinear dynamic systems that are sensitive to initial conditions, exhibiting chaotic motion. Sensitivity to the initial conditions means that two such systems with however small a difference in their initial state eventually will end up with a finite difference between their states. The chaotic motion is governed in the case of seismicity by a spatial attractor, i.e. the final state of a seismic movement is at rest (zero velocity and acceleration) but varying in space.

Hurricanes and cyclones, like seismicity, also demonstrate chaotic behaviour. Small changes in the temperature in and around a hurricane can shift its path in a predictable direction, or slow its winds. Some researchers are considering ways ranging from seeding clouds to using satellites to collect solar energy to supply heating that will alter and manage hurricanes (Hoffman, 2004). If there is hope for managing hurricanes, surely there is the same for seismicity?

The importance of chaotic character is that changes made to initial conditions influence the final outcomes (the event magnitudes). What are the initial conditions in the seismicity context? As time passes, excavation is imposed on top of the pre-existing rockmass constitutive properties, namely the premining stress regime, the rock properties, and the geological 
faults and structures (strength, shape, stiffness). Changes made to factors such as excavation geometry, position, mining sequence, and blasting procedure will influence the final seismic outcome of the excavation.

This suggests that analysis of initial conditions and the resulting seismicity can be expected to improve the ways of effectively managing mine seismicity. The initial conditions are not known to the required resolution to be able to predict individual chaotic rockbursts. However the gross boundaries of the initial conditions can be identified, and studied to examine how they affect seismicity on a global as opposed to individual basis.

Section 5 below presents this kind of analysis undertaken for Mt Charlotte. Clearly such analysis is not possible without collecting and presenting data on the initial conditions.
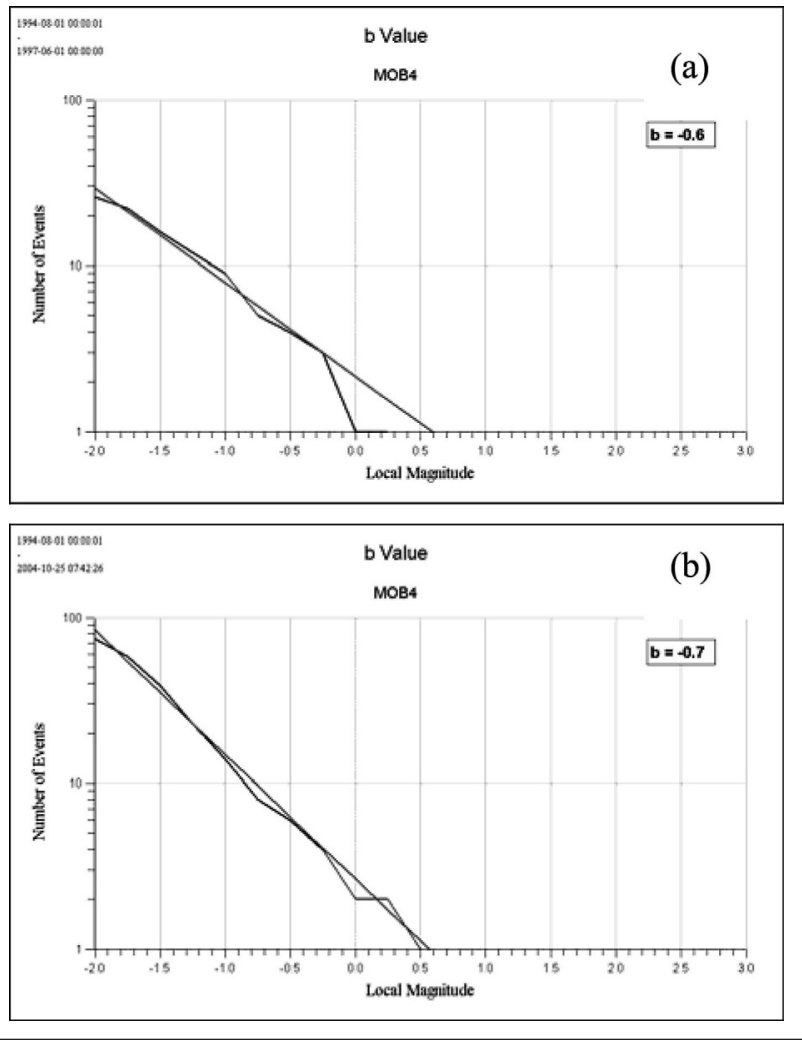

FIG. 2 B-value diagrams for the MOB4 stope backs cluster. Fig $2 a$ (upper) shows the b-value was -0.6 from start of mining until 1 June 1997. Figure 2b (lower) shows the b-value for the entire mining period to December 1997 was similar at -0.7 , but the maximum recorded event magnitude was greater

\subsection{Using a Seismic Monitoring System}

Collecting seismic event data is a joint effort between computers and engineers. Computers do a good black box job of collecting seismic event data. However having waveform signals and seismic source parameters listed on a computer database is not the key to understanding mine seismicity. The black box is no help to the engineer if its information is not understood.

Seismic monitoring does not end with the daily printout of piles of data. The monitoring task is not complete until every event is recognised and understood. The data must be processed into a form useful to the human mind, which is good at heuristics but poor at multivariate deterministic analysis.
Given the fractal nature of event clusters, the processing need is for a method to allocate event data into event clusters:

- Spatial and temporal clustering is very ably done by the MS-RAP software program (Hudyma et al., 2003). Most engineers would find the raw data in Figure $3 a$ less attractive than the clustered data in Figure $3 b$. MS-RAP is a simplistic yet powerful tool using seismic source parameters to jump the gap and arrive at a better understanding of mine seismicity. Clustering cuts thousands of events to only dozens of clusters.

- Other forms of clustering could be used, eg. based on stress states, energy states, or fault alignments.

A work schedule to ensure clustering is done is also necessary. The schedule must function perfectly in the busy mine office scenario - too busy to not have good systems. At Mt Charlotte where the event rate is low, the seismic update is done first thing every morning, and MS-RAP is run weekly to update clusters. In more active mines MS-RAP can automatically update clusters, making analysis easy. Unfortunately as noted by Hudyma et al. (2003) analysis is not usually or even often done because mine staff are:

- Too busy - Effort, time and expertise not available or not justifiable.

- Not interested - Techniques not intuitive or considered unproven.

- Not trained - Inadequate tools and training to undertake detailed analyses.

- Not sure - Analysis results ambiguous or inconclusive - difficult to relate analysis results to what is seen underground.

These perception problems must be overcome by mine management if proper expertise is to be developed.

\subsection{Underground Observation and Stope History Data}

As excellently described by Lee et al. (1989) for the Mt Charlotte environment, "Stopes, Stresses, and Structures" make up the initial conditions influencing a seismic event. Therefore the proper study of seismicity requires collection and presentation of this initial condition data. At Mt Charlotte this is done using the following system of work:

- Every underground workplace visit is documented on a mudmap, with checklist for the key

- geotechnical factors expressed at the site. The essence of this task in one word is "Look!" Beck (2002) offered several examples (to which the author has added a couple more):

- Check all development drives near current mining for cracks, loaded bolts, rocknoise, borehole breakout.

- Check all the fault intersections for how the faults are moving, i.e. whether fault-slip is occurring. If not moving, are faults showing signs of strain or producing scats?

- Are the faults doing what was expected? Are they locked? A locked fault won't move, but neither will a fault under no stress at all.

- Is there any disconfirming evidence to suggest assumptions might be erroneous?

- Recall the changes that happened before previous large events - are there any such changes this time?

- Look twice at the rock, to be sure that the full geotechnical environment is correctly understood. 


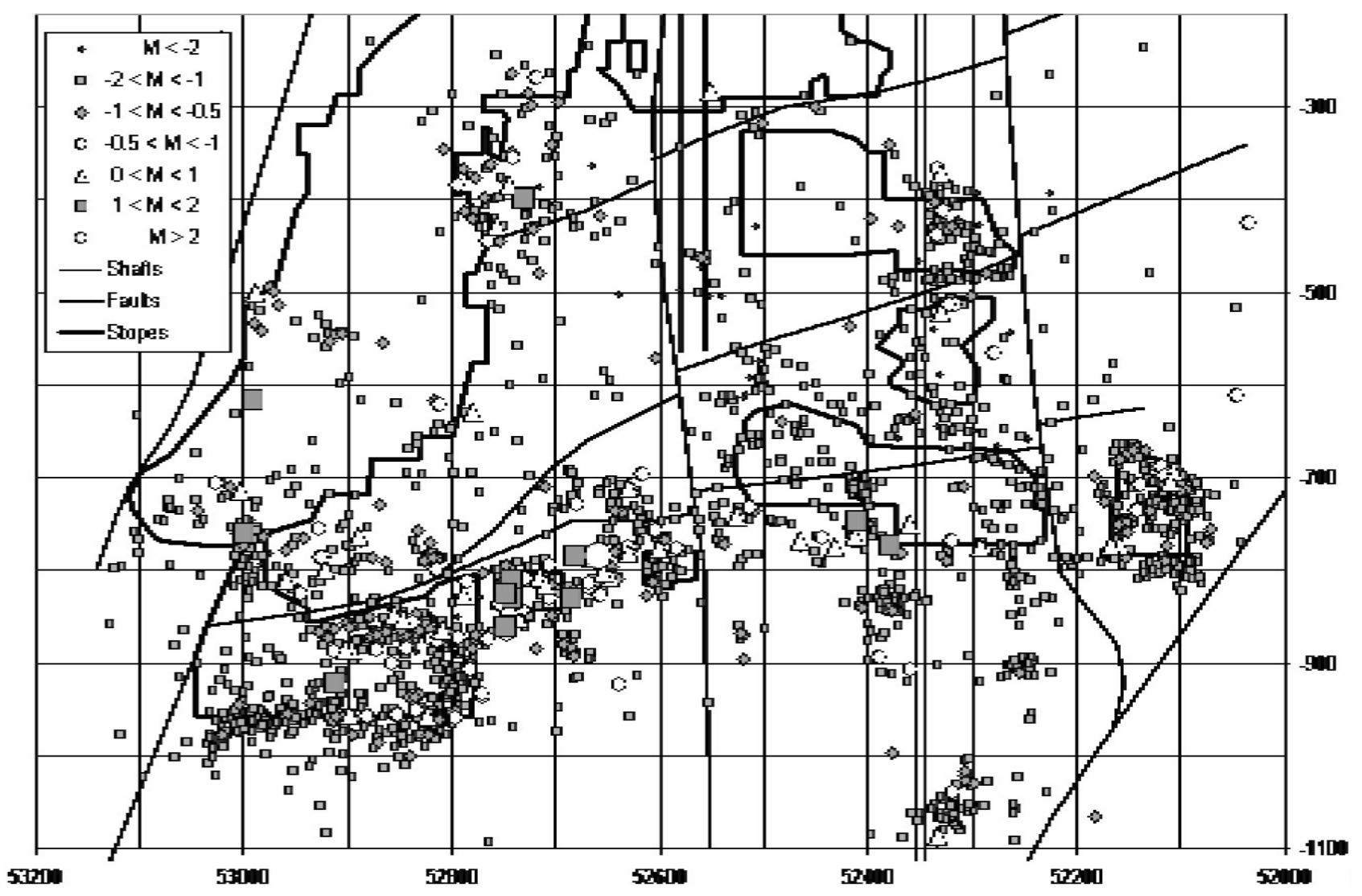

FIG. 3a A longitudinal projection showing the location of the 2000 seismic events at Mt. Charlotte between 1994 and 1998

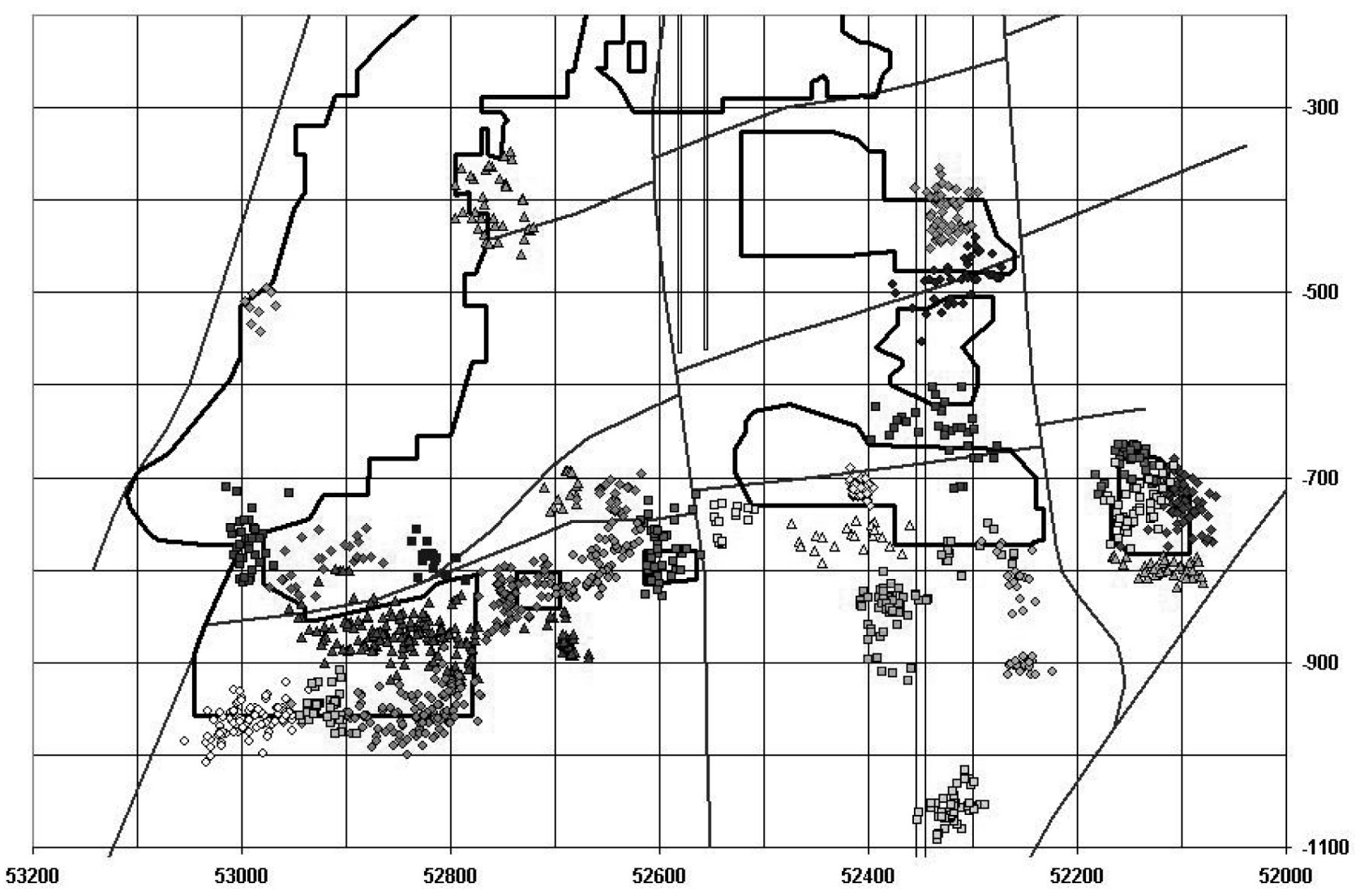

FIG 3b A longitudinal projection of Mt. Charlotte mine showing the location of 28 clusters of seismic events as generated by MS-RAP. The 28 clusters represent $65 \%$ of the total number of events at Mt. Charlotte, but contain more than $96 \%$ of the seismic energy recorded during the 5-year period 
- A monthly reconciliation of workplace visits is prepared - comparing design expectations with actual performance.

- As the months pass, a history of stope performance is built up - exactly what is needed for later analysis of seismic response.

\section{FORMULATING DESIGN PRINCIPLES}

Approach and analysis are the two sides to generating design principles. Turning collected data into design principles requires approaching the task in a supportive attitude, and thinking carefully about the analysis, as discussed in the following sections.

\subsection{The Approach to the Task}

- Despite personally being familiar with only a few large events or pillar failures, the author often (partly intuitively) correctly forecasts the seismic outcome of a given piece of mining. This knowledge does not just happen, it was fostered and developed in a suitable environment. How? Here is the grab-bag answer to the question, "what did you do to become a forecasting expert?"

- Use natural advantage - Mt Charlotte in a sense is a good study mine, with essentially only one rock type and two dominant fault and structure orientations. This simplicity allows better perception of the importance of other parameters.

- Have continuity - The author has spent over 12 years at Mt Charlotte - long enough continuity to see several complete stoping exercises, and to see the results of designs and plans made some years previously.

- Monitor - Nearly 11 years of this time is with the invaluable support of a seismic monitoring system. The PSS is a mine-wide macro-seismic system, and rarely recorded more than 20 events per day. Although limiting in other ways, this uniquely permitted individual attention to and analysis of every seismic event without exception - a major factor in developing the author's understanding of Mt Charlotte seismic behaviour.

- Investigate - The author has experienced mistakes, including several large events. Failure can be deadly if ignored, but beneficial if studied. "A wise man is one who has made many mistakes. A fool is one who makes the same mistakes again."

- Observe - Learnt to interpret underground observations and seismic signatures as signs of what lies ahead. Rock reveals its hand early. As soon as development is mined, the seismic character of the ground is apparent, even if the magnitude of later events is not. For example, Figure 4 shows the b-value and maximum expected event magnitude for four clusters as a history path. This is discussed further below.

- Research - Undertake a high level of study and research, lest the seismic situation be the same in 5 years time. Trials, tests, changes are normal. A group of informed dedicated people, both on the mine and in research and academia, is part of managing seismic risk.

- Beware optimism - There seems to be a natural tendency for people closely involved with a particular risk to be more optimistic than those who are just looking on. Familiarity breeds contempt. Therefore have a good but pessimistic consultant, and ensure regular reviews of work.
- Talk - Communication between engineers and operators needs to be excellent, two-way and regular. Always take time to explain situations to underground operators using a drawing or two. If they ask good questions about it, progress is happening.

- Publish - Give away information. As information circulates, the geotechnical fraternity is better placed to make global advances that will benefit all. Publish often, as this crystallises thinking. Go to a good geotechnical conference at least yearly.

- Visit - Have many visitors and listen to them. It is not a case of "I've heard it all before" which translated means "I am not interested in changing, so why bother?" Rather it is "How can I take another step forward?" No-one has time to make all the mistakes themselves. "People learn from one another, just as iron sharpens iron." (Proverbs 27:17)

- Document - Keep very good stope record systems to manage the problem of changing personnel and loss of historical mining knowledge. Have meticulous attention to details - stopes, sequences, stresses, structures, schedules, shearing, support. Have mine plans up-to-date with all faults and accurate current stopes, pillars and development.

- Be humble - Recognise miscalls as such, knowing that there is much more going on than is apparent.

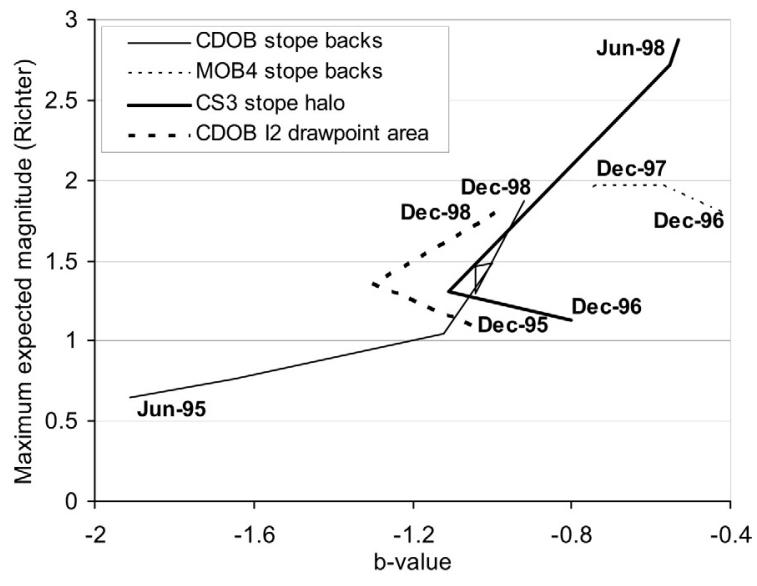

FIG. 4 The b-value versus maximum expected magnitude history path for four groups of clusters, over cumulative 6-monthly periods totalling one to three years as indicated. The MOB4 stope clusters showed a stabilising cap. The CS3 and CDOB I2 clusters both showed an initial stabilising trend until approaching production mining changed the seismic response. The CDOB stope back clusters showed a one-year back-pedal that commenced when production in the area ceased, and ended following seismicity in another nearby stope

\subsubsection{Doing research - Stress change monitoring experiment}

Mt Charlotte has had four very useful HI cell stress monitors active since 1995 at the base of the Cassidy shaft (1.2 km deep and remote from stoping) searching for regional stress field variations. The cells have returned intriguing but low resolution data hinting at multiple stress changes of up to $1 \mathrm{MPa}$ over time, changes apparently unrelated to mining. The next phase should be suitably sensitive monitors at two different minesites, which could open the window on earth gravity tides and tectonic stress changes, and their relationship to mine seismicity. 


\subsubsection{Doing research - Electromagnetic emissions (EME) experiment}

Electromagnetic radiation at very low frequency has long been observed prior to earthquakes. It is thought that crack formation due to stress increase or stress relief is the source of the radiation. In June 1996 an experiment was conducted on 26 Level during the CDOB I2 stope mass blast, to search for EME associated with fracturing of rock during seismic events (O'Keefe \& Thiel, 1996a, 1996b). This experiment was a first step in assessing whether radiation may be a useful indicator of impending seismicity. Radiation was indeed detected, showing the sensitivity of the technique, and some EM events and seismic events were correlated. EM events indicating extensions of long cracks were seen.

Shortfalls in the then available equipment made analysis difficult, as computer response times were too slow to handle the huge volumes of data. A repeat experiment conducted not during a blast, and with improved hardware configurations, would yield positive results.

\subsection{The Analysis of the Data}

Analysis is the second side to generating design principles, and it needs to be done carefully and sharply to divide the complexities of seismicity.

In the seismicity context, the aim when designing stopes is to anticipate any zones (clusters) of likely activity of a particular character. It is not usual to forecast details of a specific event. Therefore back-analysing existing seismic data naturally should start with monitored documented event clusters and their characteristics. This is why analysis should concentrate on clusters, and not on the total event cloud or sole large events. Study the forest, not the individual trees.

Often, a simple study gives the most understanding Mt Charlotte uses MS-RAP for initial simple seismic source parameter analysis of clusters, leading to broad definitions of source mechanisms and hazard implications. Figure $3 \mathrm{~b}$ shows Mt Charlotte events sorted into clusters.

The next step is heuristic, where the computer is the servant, not the master. Find and explore the links between the initial conditions and the cluster seismic character. This takes focussed thinking, no less. De Bono (2004) suggests that we need to spend time learning how to think our way to new solutions:

- List the "way out" ideas

- Consider and evaluate all options

- Never just take the first viable option and forget the rest

- Take criticism - ask people why it won't work

- Test and challenge the ideas - this was done as a comprehensive study, outlined in Section 5.2 below, for Mt Charlotte event clusters and initial conditions, and yielded interesting results.

De Bono's six thinking hats are:

- Intuition, hunches and feelings.

- Information available and needed, facts and data.

- Benefits, value and positive aspects.

- Alternatives and creative ideas.

- Caution, difficulties, risks and weaknesses.

- Managing the thinking, focus, summary.

In the underground mining framework, engineers need to always jot down possible reasons for any observed lack of ground control, and be in the habit of seeking mechanisms. Beck (2002) gives the following examples of searching for mechanisms:
- Analysis by contouring of where events occurred relative to the advancing blasting sites, found two clusters, and distinguished blast-controlled events from overall mine geometry events.

- Analysis by preparing histograms of event distance to the stoping front revealed what was going on at what distance, guiding support, and showing where ground was on the stress curve.

After possible seismicity explanations are defined, it may be helpful to follow up with carefully planned numerical modelling.

\section{THREE DATA ANALYSIS STUDIES}

\subsection{B Value History Path Chart}

Figure 4 presents the b-value and maximum expected event magnitude for four groups of Mt Charlotte clusters, plotted as a history path. This shows important lessons:

- The seismic character of the ground quickly becomes apparent when excavation starts, even if the magnitude of later events is not.

- Large changes in b-value and magnitude occur over time as seismic domains are crossed. It is necessary to define seismic domains (just like geotechnical domains) for different temporal sources, as well as spatial sources.

- Maximum expected magnitude and b-value can vary independently.

- As the geometry is changed, larger events can occur, which is the reason to be concerned about mining method, design, and sequence. For example as a stope grows and influences more surrounding ground, and a large fault starts governing behaviour, a cluster can no longer be restricted to near neighbours.

- B-value could be regarded as a measure of likelihood, and maximum expected magnitude as a measure of consequence, to obtain a qualitative hazard rating.

\subsection{Linking Cluster Characteristics and Excavation Initial Conditions}

Psychological studies have found that individuals tend to make irrational decisions, based on many factors which need not include all or only the relevant information. People have a tendency to subjectively emphasise recent experience or successes at the expense of prior history, as seen for example in runs on the stockmarket. The temptation to subjectively jump to conclusions and allocate blame is also well known in accident investigation scenarios.

Therefore any tools which can attach objective handles to relevant seismicity information should be sought and used. The MS-RAP program does this for event clusters, and the Mt Charlotte "14-Rules" - the mine's original Seismic Risk Reduction Checklist - was an attempt to do the same for assessing the specific links between seismicity and stope designs, stresses and structures (Mikula \& Lee, 2002).

A study was undertaken recently at Mt Charlotte to test and improve the 14-Rules. This study developed seismic knowledge. The rules are now recognised as a Seismic Hazard Management checklist, and seven more have been added as a result of the study (Table 1 ). The rules are based on empirical experience, and if valid can be used to advantage in designing to reduce the seismic hazard.

Are these rules a lot of hot air with emotional attachment, or are they real handles for managing seismic conditions? The reality of any cause-and-effect link between the rules and seismic expression is what is important. To test the validity of the rules, an intensive study was undertaken as follows: 
TABLE 1 The 21-Rules Seismic Hazard Management checklist at Mt Charlotte. For extended descriptions and examples refer Mikula \& Lee (2002). The table also shows the study findings in terms of those rules that appeared to be contributing factors to cluster event magnitude

\begin{tabular}{lll}
\hline Rule name & Brief Description & Rule Findings \\
\hline 1 Backfill & Degree of stope wall support & Useful \\
2a Local "Lumpiness" & Stiff protrusions, lumps and pillars act as stress raisers & Useful \\
2b Regional stiffness / wedges & Presence of fault wedges around stopes & Useful \\
2c Regional stiffness / voids & Size (softness) of stope voids & Useful \\
3 Access positioning & Development access intersecting or exposing fault lines & Ambivalent \\
4 Unlock faults quickly & Stope sequence unlocking faults to allow movement & Useful \\
5 West-dipping structures & Presence of significant west-dipping faults / structures & Useful \\
6 Abutment access & Orientation of access drives in stope abutments & Ambivalent \\
7 Stress path on faults & Consideration of normal and shear stress on faults & Useful \\
8 Abutment stress & Width of high stress stope abutment & Ambivalent \\
9 Diminishing pillar / abutment & Presence of diminishing pillars and abutments & Useful \\
10 Blast size & Size of production blasts & Ambivalent \\
11 Preconditioning & Application of preconditioning & Ambivalent \\
12 Destressing & Application of destressing & Ambivalent \\
13 Blast timing & Previous events tending to occur during blasts & Ambivalent \\
14 Reoccurrence & New events reoccurring near previous events & Ambivalent \\
15 Event type & Distinguishing fault-slip, strainburst and breakout & Ambivalent \\
$16 \%$ Extraction local & Local void as seen by principal mining stress & Useful \\
17 \% Extraction regional & Regional void as seen by principal mining stress & Useful \\
18 Void ratio & Ratio of local/regional percentage extraction & Useful \\
19 Pillar type & Distinguishing crown, rib and fault-abutment pillars & Ambivalent \\
20 Pillar shape & Pillar width/height ratio where applicable & Useful \\
21 Depth factor & Depth below surface as indicator of stress level & Useful \\
\hline
\end{tabular}

- Every seismic event cluster was listed along with key source parameter characteristics (b-value, maximum expected magnitude, median S:P ratio, $\log E / \log M$ )

- Historical and environment information for each cluster was added (stoping block, year/s of activity, geologic faults, descriptive comments)

- Each of the 21-Rules was scored for each cluster, the score ranging from 100 for the rule being perfectly followed, to 0 for the rule being fully ignored. For example for the first rule, dealing with backfill, the score was 100 for a development site, 90 for a backfilled stope, and 0 for an open void stope.

- Charts of individual cluster parameters versus rule scores were developed and inspected for trends.

- Any clusters with incoherent data (unable to compute a b-value; too much scatter in $\log \mathrm{E} / \log \mathrm{M}$ ) were discarded.

- Any rule parameters showing no useful trends were discarded, and the remaining parameter scores were averaged and plotted.

Then the whole exercise was repeated for the 33 largest recorded individual seismic events instead of the clusters. The premise was that because the large events were less representative of their respective clusters, a poorer correlation between event parameters and rules scores should be obtained. Individual events can vary from the expected cluster characteristics.

Accurate trending is difficult to achieve, so it was encouraging to obtain some useful charts. These charts show significant scatter, the more so for the individual large event results, as expected. Magnitude and b-value were the only event parameters contributing to useful trends. Experience is captured on paper - some of the resulting graphs are shown in Figures 5 to 7 . These findings were used to improve the Mt Charlotte seismic design principles, by creating an improved 21-Rules checklist for use at the mine.

The next study phase will be to run Map3D models for the clusters to obtain Loading System Stiffness, which is expected to be a good indicator parameter. Source Stiffness, another indicator, will be obtained from further processing of the seismic event data.

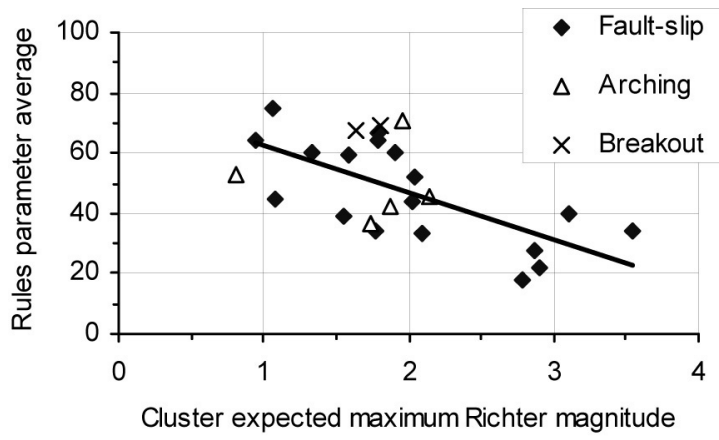

FIG. 5 Chart of clusters showing expected maximum event magnitude (from the b-value charts) plotted versus the average parameter score for the selected 21-Rules for the cluster. Data is subdivided by type of event. The chart shows considerable scatter, yet a clear trend linking parameter rating to seismic outcome

\section{CSOM Analysis}

Over the past two decades substantial progress has been made in the field of computational data mining. Tools are being developed to explore the relationships within the various input fields of vast databases, and seek out critical knowledge. The Self Organizing Map (SOM) method (Kohonen, 2001) has been widely used for data analysis in 


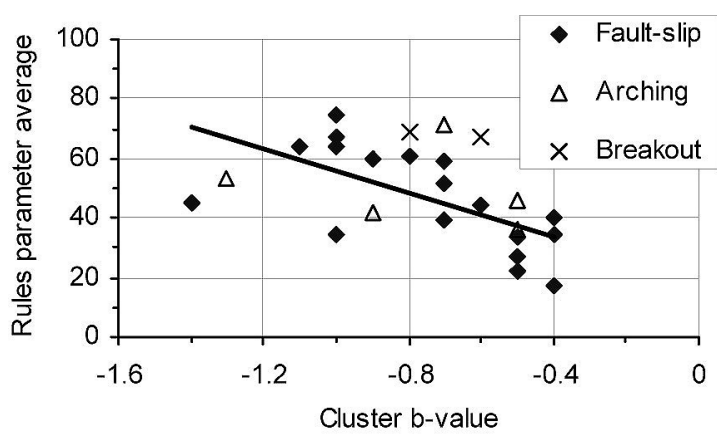

FIG. 6 Chart of clusters showing b-value plotted versus the average parameter score for the selected 21-Rules for the cluster. This chart shows greater scatter than that in Figure 5 , and is not as useful for forecasting purposes

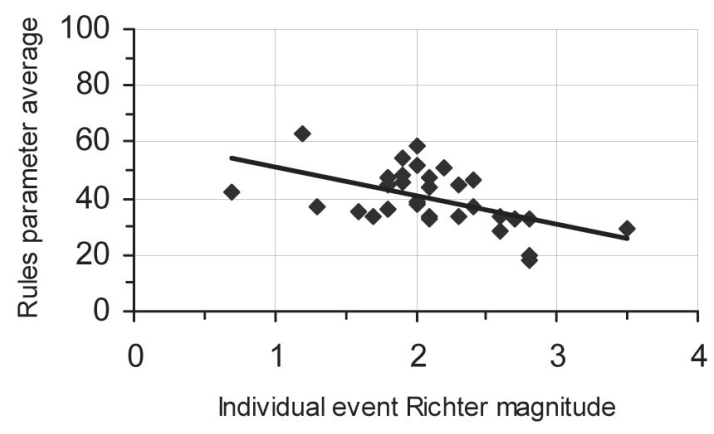

FIG. 7 Chart of individual event magnitudes (for 33 selected larger events) plotted versus the average parameter score for the selected 21-Rules for the event. This chart shows a flatter (less useful) trend line than that in Figure 5

the fields of finance, industrial control, speech analysis, and astronomy. The petroleum industry is using SOM to assist interpretation of drill-logs and seismic data. Dickson et al. (2004) reported on the use of SOM to recognize lithologies from the analysis of bore hole geophysics.

CSOM (CSIRO Self Organising Maps), a data mining tool developed by the CSIRO, is being used to analyse the Mt Charlotte seismic data (Fraser, 2004). A preliminary trial was run to gauge the suitability of the 21-Rules database for CSOM analysis. Figure 8 shows the resulting Component Similarity Plot, and on this display the 21-Rules parameters are positioned according to their correlation with each other and their impact on the overall analysis. Clear correlations are seen, and on this basis a full study of the data is currently in progress.

SOM is based on the principles of vector quantisation and measures of vector similarity. In a SOM analysis, each sample is treated as an n-dimensional vector. This sample vector quantization approach means that data that is continuous (e.g. Richter magnitude), categorical (e.g. presence of backfill in a stope), and very diverse (e.g. the disparate types of data listed in Table 1), can be input to the one analysis, making $\mathrm{SOM}$ an ideal tool for the analysis of geotechnical data sets. Because the SOM is unsupervised, no prior knowledge is required as to the nature, or number, of groupings within the data.

These features make the SOM technique attractive compared to other analysis methods such as clustering (both hard and fuzzy), factor analysis, principal components and multiple linear regressions. It has exciting potential to improve design stage seismic forecasts.

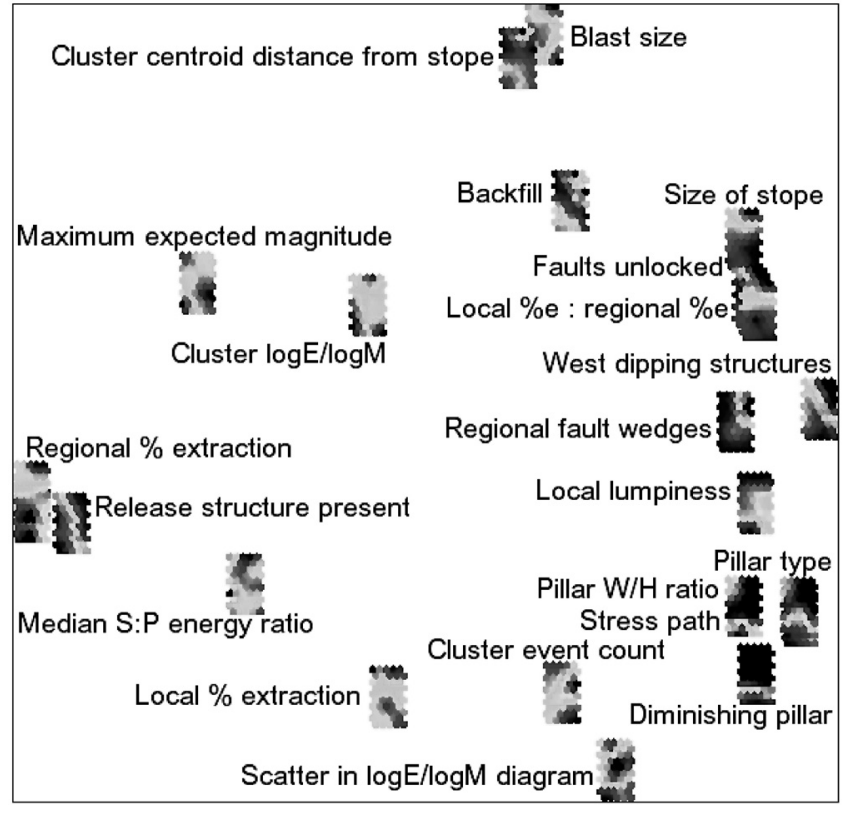

FIG. 8 CSOM analysis of Mt Charlotte 21-Rules data, showing the PC\#1 vs PC\#2 space projection which illustrates the "Similarity of the Component Inputs"

\section{PRACTICAL SEISMIC MANAGEMENT}

Rock is not like steel and concrete. Rock has extra complexity and variability which even if globally estimated is locally unknown. The nature of rock invites special study, knowledge, and methods. Successful designs must allow for variability of rock, errors and unknown factors, so the geotechnical engineer has a critical role in hazard management. The Seismic Hazard Management Plan is a statement of the action plans used to manage seismic hazard, and is part of the mine's Ground Control Management Plan.

Seismic management encompasses both the initial excavation design phase, and the mining phase.

\subsection{Seismic Hazard Management in the Initial Excavation Design Phase}

The essential process used at Mt Charlotte to assess the design of a new excavation or stope relies on two tools, the 21-Rules and the chart in Figure 9, to arrive at an idealised stope design as follows:

- Assess the new stope design according to the 21-Rules, identifying the contributing factors to maximum event size.

- For every geological fault in or near the stope, estimate the area of that fault surface that will experience a stress change of greater than $5 \%$. This is regarded as the possible slip area, and is used to compute a maximum expected fault-slip event magnitude using the chart in Figure 9 (Gibson, 1998).

- If large seismic events (Richter 2.2 or more) are forecast, intervention is required. Change elements of design and/or sequence as practicable to deal with the identified contributing factors. For example, if a pillar containing a fault cannot be avoided, change mining plans to ensure that the fault in the pillar is not clamped. The intent is to remove or hinder the mechanism of the largest events.

- Use numerical modelling appropriately to support proposed designs or to quantify the differences between competing designs. 
- Define ground support, re-entry windows, personnel access controls, and any other stoping constraints, with appropriate Standard Operating Procedures.

- Document specific locations around the stope where seismicity could be expected under possible scenarios, for instance if faults lock up on asperities or offsets, or move freely, or if low regional stiffness permits stresses to build up around the stope.

Repeat the assessment process for any subsequent changes made to the initial design to suit the mine's changing requirements.

This process allows for possible unknown factors and unexpected variability in rockmass characteristics, by nominating a Richter 2.2 magnitude as the upper tolerable event size. This magnitude is less than the magnitude (Richter 2.5) of the largest stope blasts at the mine, and has tolerable damage and surface vibration levels. This conservatism equates to the cathedral stonemasons' factor of ten in their dimensioning specifications.

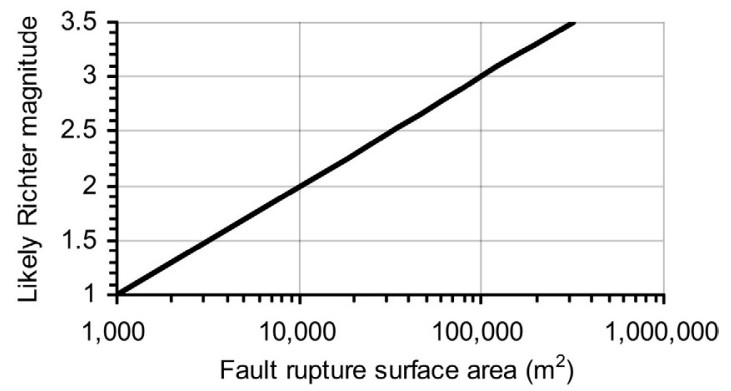

FIG. 9 Simple relationship between fault rupture surface area and likely maximum event magnitude

\subsection{Seismic Hazard Management in the Mining Phase}

During stoping, do the following:

- Plot events versus time to monitor seismic character.

- Define seismic hazard on the basis of MS-RAP clustering of seismic monitoring data as it becomes available.

- Explore reasons for any differences between expected and actual locations of seismicity.

- Watch for events "unexplained" by blasting, either spatially or temporally, as these can indicate elevated fault-slip potential.

- If stoping experience indicates increased seismic hazard, respond by assessing options with management and engineers, particularly if intervention becomes necessary. The situation is similar to open pit slope monitoring - if cracking is detected, the mine response plan is activated.

It may be that during mining, increased seismicity appears inevitable. If so, there are three management options available. These are to attempt to have the seismicity occur as follows:

- At a chosen time, ie. during blasting. This is easier to achieve for stress fracturing than for fault-slip events.

- At a chosen place, which is much harder to achieve.

- At a chosen magnitude, done by controlling fault-slip area, or modifying rock stiffness by preconditioning or destressing (Mikula et al., 1995). Current Mt Charlotte experiments using Tight Slot Blasting to reduce expected event magnitudes are described in another paper in this Symposium (Mikula et al., 2005).
At the end of the day, be conservative and smart. There are old pilots and bold pilots, but there are no old, bold pilots. In this regard it should be of benefit to look at the thorny problem of forecasting of large seismic events, and at a good example of hazard management.

\section{WEATHER FORECASTERS AND SEISMICITY}

The author has found at Mt Charlotte that it is difficult to forecast the larger seismic events. Weather forecasters have the same problem. In climates where rainy days are few and far between, forecasting rainy days has a large error rate. This has partial similarity to the forecast of the largest seismic events, which are also few and far between.

Following the example given by Matthews (1997), suppose a climate generates a known pattern of 5 rainy days and 360 sunny days per year. Also suppose forecasters select the correct weather for the day on $80 \%$ of days. Thus:

- Of 5 rainy days, 4 are forecast to be rainy, and 1 sunny.

- Of 360 sunny days, 288 are forecast to be sunny, and 72 rainy.

Then

- A sunny day forecast is wrong on 1 day and correct on 288 days per year.

- A rainy day forecast is wrong on 72 days and correct on 4 days per year, which is about a $95 \%$ failure rate. It is far easier to forecast the yearly average climate than the specific storm.

So it is with seismicity forecasting - practitioners should be cautious when arriving at their assessments. Forecasting typical cluster behaviour is easier than forecasting a specific large event. This is a well-known phenomenon, seen for example in b-value diagrams (Figure 2), where it is apparent that the largest half-dozen events can appear quite erratic, while the rest settle down to follow the b-value trendline quite well. The expected and actual largest event magnitudes often differ, as summarised in Figure 10 for Mt Charlotte clusters.

Regardless of what the statistics say, Mt Charlotte management and operators are firmly of the opinion that "If Pete says it's OK, then it is." The author finds this intriguing, and it perhaps could be another subject for future interesting research.

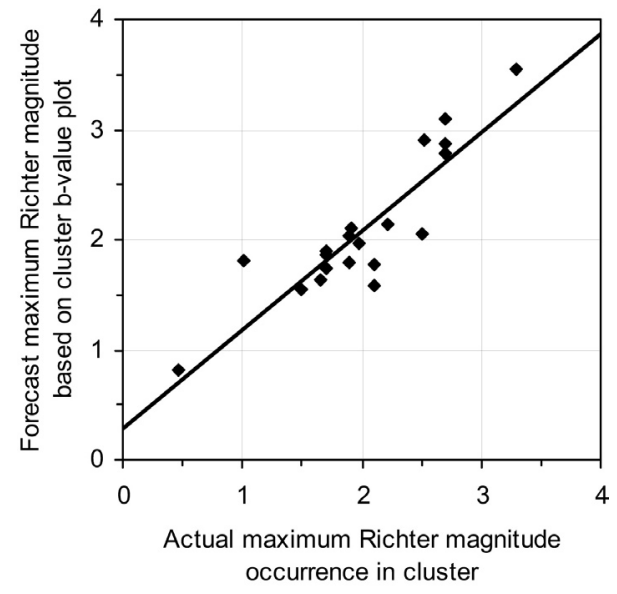

FIG. 10 Comparison of the expected maximum event magnitudes (from the b-value charts) versus the actual maximum magnitudes for that cluster as experienced during mining 


\section{ILLUSTRATION FROM AUSTRALIAN FOOTBALL LEAGUE (AFL)}

Having no mine seismic monitoring system is like having an AFL team without a coach. The following allegory serves well to illustrate many of the points made in this paper.

The football in the AFL game can be regarded as the packet of stored energy in the rock. The velocity of the football equates to its dynamic potential, and the ground is the trigger mechanism that releases the seismic event. The team players are the seismic management plan, while the opposing team players are the mine environment. The objective is to always be in control of the football.

What are the risks?

- Never quite know how the non-spherical football will bounce - the interaction of all the factors makes every bounce unique, just as every seismic event is unique.

- Need to watch for and defend against opposing team players - be aware of unexpected variations that can and will arise from the mine environment.

What are the strategies?

- Need enough players to deal with whatever the football does or whatever the opposing team players do - need a practical robust seismic hazard management plan.

- Have sufficient practice - continuity of experience, exposure to all facets of the mine's seismic behaviour.

- Have a core of players with many games of working together - have a stable core of dedicated informed engineers with excellent communication with management and operators.

- Have sufficient high-quality training - need a comprehensive seismic hazard management plan.

- Have a good coach and videos of the games have good quality observations of seismic events and initial conditions, and assess them to give clear pointers for improvement.

What could make it easier to control the football?

- Make it bounce slowly - design a stoping plan that is not able to deliver much energy.

- Make it softer - mine in ground not able to store as much energy.

- Make it round - easy to predict what will happen, perhaps like mining in concrete - but then it's not AFL.

- Make the ground softer, yielding and absorbing energy - install dynamic capable support.

- Catch it - have the best players - perfect design that avoids seismicity totally.

- Have players skilled at very fast response - install dynamic capable support.

Clearly, to control the football and win the game requires years of dedicated coaching, planning and training. The geotechnical engineer likewise is in the role of a dedicated coach for the mine staff and operators, managers, peers, and students. And supporting the geotechnical coach are the seismic monitoring system and the documentation based on underground observations, which are the basis of the seismic hazard management plan of the mine.

\section{HOW SEISMIC MONITORING HAS CHANGED MT CHARLOTTE}

Two benefits of having a seismic monitoring system in a mine are usually given:

- Reduced seismically related production delays (more assured production), and

- Improved mine safety.
But there's more. Here are the other benefits in the case of Mt Charlotte:

- Dramatic reduction in seismicity achieved.

- Seismicity is part of the mine vocabulary.

- Seismic management is part of every work item.

- Chasing lower costs is subservient to consideration of seismic potential.

- Appropriate mining method changes have been introduced.

- Extraction ratios are improved, by mining pillars and orebody extensions that have previously been left due to seismic risk - better use of finite mineral resources.

- Seismicity is correctly managed without much additional cost.

- There is greater profitability in the ways orebodies can be mined.

- There is confidence to go against usual practice and intentionally fracture good rock or blast tight slots to manage seismic hazard (Mikula et al., 1995, Mikula et al., 2005).

- There is guidance for extrapolating designs to future greater depths and higher stress environments.

- Finally, the mine is still open, despite a history of "closures."

\section{WHAT MT CHARLOTTE COULD HAVE DONE BETTER}

In hindsight, several things could have been different:

- A more dense geophone array would have been of benefit. The PSS is a macroseismic mine-wide system, collecting barely enough of the lower end events to assess seismic character. The lower end sensitivity is -1.8 local magnitude, whereas a figure of -2.5 to -3 would have been useful. Rather than the 10 triaxial sensors installed, a spread of uniaxial and triaxial sensors would have suitably increased the sensor density.

- The ability to automatically allocate events into clusters was missed now that MS-RAP is available. Performing manual clustering by searching the database was tedious, imprecise and not always done.

- More detailed records should have been kept. The author collects and keeps much more information now than 10 years ago. Basically the full design, drilling, blasting, production and geotechnical behaviour history of every stope needs to be documented.

- More stress change monitoring would have been helpful (refer section 4.1.1).

- A further EME experiment is warranted (section 4.1.2).

- Hundreds of events have been monitored between $1 \mathrm{~km}$ and $4 \mathrm{~km}$ from Mt Charlotte, where no mining is going on. They could be long-term stability or instability indicators. A study of how they might be related to mining could add to understanding of seismic hazard.

\section{CONCLUSIONS}

Eleven years of seismic monitoring has been the foundation for the current understanding and management of seismicity at Mt Charlotte mine. Knowledge gained by linking seismic monitoring to seismic management has allowed the mine to survive. 
This paper explored some unusual yet important parallels between mine seismicity and Gothic Cathedral constructions of the 13th and 14th centuries, weather forecasting, and AFL football. The Cathedral stonemasons learnt how to allow for the unexpected. The weather forecasters struggle with high error rates in forecasts of rare events. AFL footballers practice a level of teamwork and hazard management that should be the envy of many mines. More than that, having no mine seismic monitoring system in a seismic mine is untenable it is like having an AFL team without a coach.

Seismic events possess elements of both fractal and chaotic behaviour. This is extremely important, as it provides a valid basis firstly to collect seismic data, and secondly to expect to manage seismicity by tweaking the initial conditions (which are the elements of the mine design that interact with the geotechnical environment - stopes, stresses, and geologic structures).

Collecting seismic event data is a joint effort between computers doing the black box work, and engineers doing the value-adding. Event data must be allocated into event clusters, such as is very ably done by the MS-RAP program. Wise engineers will also have a work schedule to ensure this is done despite the busy mine office scenario.

Seismic monitoring data provides only half the picture. The other half is the detailed history of stope performance, which can be built up from a monthly reconciliation of workplace inspections for stress, structure and stope information. Collecting and studying this information is a large part of the process of crystallising knowledge into expertise. Also essential to developing expertise is adequate thinking, by study and assessment on paper of every stope design, every large seismic event, every event cluster. A computer simulation is necessary to support thinking, not to substitute for it.

A Seismic Hazard Management Plan is a suitable tool for seismic hazard management both in the initial stope/ excavation design phase, and in the mining phase. It needs to have conservatism to allow for variability, errors and unknowns.

Even though in hindsight, several things could have been done better, Mt Charlotte has enjoyed many benefits flowing from the seismic monitoring system.

Positive results emerged from the study investigating the links between seismic expression and those by now well worn initial conditions of stopes, stresses, and geologic structures. The result has improved the value of Mt Charlotte's 21-Rules for seismic design. Further exciting projects such as the CSOM work are in progress. Studies such as these suggest that there is truth in the author's opinion that "now I know something about seismicity." None of this could have been possible without that black box untiringly listening for every seismic event underground, and in that sense the author can say, "I love my Seismic Monitoring System."

\section{ACKNOWLEDGMENTS}

I am not a solo performer! "In everything you do put God first, and he will direct you and crown your efforts with success" (Proverbs 3:6). May I also acknowledge Max Lee in the invaluable role of mentor and pessimistic consultant, and the input of Glenn Sharrock, Dion Fotakis, Dave Ortlepp and Marty Hudyma in focussing my thinking over the years. I am indebted to the ACG continually developing synergy through timely seminars and conferences. Thank you to Graham Baird of WASM, Steve Fraser of CSIRO, to the GCG(WA) engineers network, to the many mine visitors, to the Mt Charlotte Mine managers, engineers and operators for their support and questions, and to KCGM for permission to publish this paper.

\section{REFERENCES}

Beck, D. (2002) Simplistic seismic monitoring. Informal presentation, AMC Consultants.

De Bono, E. (2004) Authorised website http:/ /www.edwdebono.com/.

Dickson, B.L., Fraser, S.J. and Sliwa, R. (2004) Knowledge from data - a new tool for analysis of diverse data. Australian Society of Exploration Geophysicists, 17th Geophysical Conference and Exhibition, Sydney Australia, 15-19 August.

Fraser, S. (2004) Proposal for Pilot Study into the Effectiveness of "CSOM" as a Predictive Tool for Forecasting Seismicity at the Mine Design Stage at Mt Charlotte, Kalgoorlie, Western Australia. CSIRO Exploration and Mining, Brisbane, Nov. 2004.

Gibson, G. (1998) pers. comm.

Hoffman, R.N. (2004) Can hurricanes and other severe tropical storms be moderated or deflected? San Francisco Independent Media Center Copy sighted at http://sf.indymedia.org/news/2004/09/1703507_ comment.php.

Hudyma, M.R., Heal, D. and Mikula, P.A. (2003) Seismic monitoring in mines.- Old technology, new applications. First AGCM Conference, Nov. pp. 209-226.

Kohonen, T. (2001) Self-Organizing Maps: Third Extended Edition, Springer Series in Information Sciences, Vol. 30, Springer, Berlin, Heidelberg, New York, 1995, 1997, 2001.

Lee, M.F., Beer, G. and Windsor, C.R. (1990) Interaction of stopes, stresses and geologic structure at the Mt Charlotte mine, W.A. Rockbursts and Seismicity in Mines (Ed: Fairhurst), pp. 337-343. Balkema.

Matthews, R. (1997). How right can you be? New Scientist, 8 Mar, pp. 28-31.

Mikula, P.A and Lee, M.F. (2000) Bulk Low Grade Mining at Mt Charlotte Mine. Proceedings of MassMin 2000, Brisbane, pp. 623-635 (The AusIMM: Melbourne).

Mikula, P.A. and Lee, M.F. (2002) Forecasting and controlling pillar instability at Mt Charlotte Mine. Deep and High Stress Mining - First International Seminar. Australian Centre for Geomechanics, Nov. 2002.

Mikula, P.A. and Poplawski, R.F. (1995) The seismic monitoring decision at Mt Charlotte Gold Mine. Underground Operators Conference, Kalgoorlie, 1995, pp. 79-85.

Mikula, P.A, Lee, M.F, and Guilfolye, K. (1995) Preconditioning a large pillar at Mt Charlotte mine. Underground Operators Conference, Kalgoorlie. (WA School of Mines and The AusIMM: Melbourne).

Mikula, P.A, Sharrock, G., Lee, M.F. and Kinnersly, E. (2005) Seismicity Management Using Tight Slot Blasting for Stress Control at Mt Charlotte Mine. Sixth International Symposium on Rockburst and Seismicity in Mines. Australian Centre for Geomechanics, Perth.

O'Keefe, S.G. and Thiel, D.V. (1996a) Report on electromagnetic monitoring at Kalgoorlie Consolidated Gold Mines Mt Charlotte Mine. Radio Science Laboratory Report 1/96, Griffith University, Brisbane.

O'Keefe, S.G. and Thiel, D.V. (1996b) Conductivity effects on electromagnetic emissions (EME) from ice fracture. Journal of Electrostatics, 36, pp. 225-234.

Vaudeville, B. (1999) The folly of structures: An apology for rigidity. Tekhnema 5 / "Energy and Chance" / Fall 1999. Copy sighted at http://tekhnema.free.fr/5Vaudeville.html. 